\title{
IMPLEMENTASI APLIKASI PEMETAAN PELANGGAN DAN PENGELOLAAN KEUANGAN BERBASIS SISTEM INFORMASI GEOGRAFIS
}

\author{
I Putu Gede Eka Suryana ${ }^{1}$, Desak Putu Diah Kumala Dewi ${ }^{2}$, Komang Kurniawan \\ Widiartha $^{3}$ \\ 1,2,3 Teknik Informatika, STIMIK STIKOM Indonesia
}

email: ekasuryana@stiki-indonesia.ac.id', desakdiah@stiki-indonesia.ac.id², komang.kurniawan@stikiindonesia.ac.id ${ }^{3}$

\begin{abstract}
Abstrak
Badan Usaha Milik Desa (BUMDesa) Catu Kwero Sedana merupakan BUMDesa yang terdapat di desa Pecatu, Kecamatan Kuta Selatan, Kabupaten Badung-Bali. Mekanisme penanganan sampah yang dilakukan unit jasa pengelolaan sampah pada BUMDesa Catu Kwero Sedana ini adalah pengambilan sampah ke rumah-rumah penduduk atau tempat usaha yang ada di desa Pecatu. BUMDesa ini menitikberatkan pada kualitas layanan yang diberikan kepada pelanggannya. Sampai saat ini masih ada keluhan para pelanggan, terutama pelanggan baru dan calon pelanggan terkait dengan awal mulainya pelayanan dan/atau pendaftaran sebagai pelanggan baru. Permasalahan yang sering terjadi adalah kesulitan mencari lokasi pengambilan sampah di tempat pelanggan. Jika pelanggan mendaftarkan diri melalui kolektor iuran yang sedang memungut tagihan pelanggan, karyawan yang bertugas mengangkut sampah yang kadang terkendala menemukan lokasi pelanggan. Selain itu, terkait besarnya tarif yang akan dikenakan kepada pelanggan. Karyawan pengangkut sampah yang tidak mengetahui besarnya tarif iuran pelanggan akan kesulitan memberikan kisaran tarif yang akan dikenakan kepada pelanggan sesuai dengan aturan yang tercantum pada peraturan desa Pecatu. Diawali dari pengumpulan data berupa observasi, wawancara dan studi literatur, selanjutnya data yang diperoleh dilakukan analisa untuk membuat model akuntansi untuk permasalahan pengelolaan keuangan serta analisa data untuk pembangunan database sebagai media penyimpanan. Dibangun sebuah sistem yang dapat memberikan informasi kepada karyawan pengangkut sampah mengenai posisi/lokasi pengambilan sampah masingmasing pelanggan, besarnya tarif sesuai dengan peraturan yang berlaku, dan rekapitulasi pembayaran iuran pelanggan. Sistem informasi ini dapat dikembangkan berbasis website dengan model sistem informasi geografis (SIG) dengan memanfaatkan fitur Application Programming Interface (API) maps yang dimiliki oleh Google. Hasilnya, aplikasi berhasil diimplementasikan serta dapat melakukan pengelolaan keuangan dan penyampaian informasi lokasi pelanggan secara cepat, mudah, dan luas.
\end{abstract}

Kata kunci: pemetaan pelanggan, pengelolaan keuangan, sistem informasi geografis

\begin{abstract}
Badan Usaha Milik Desa (BUMDesa) Catu Kwero Sedana is a BUMDesa located in Pecatu Village, South Kuta District, Badung-Bali Regency. The waste handling mechanism carried out by the waste management service unit at BUMDesa Catu Kwero Sedana is taking garbage to people's homes or business places in the village of Pecatu. This BUMDesa focuses on the quality of service provided to its customers. Until now, there are still complaints from customers, especially new customers and prospective customers, related to the start of services and registration as new customers. The problem that often occurs is the difficulty in finding a waste collection location at the customer's place. If a customer registers himself through a contribution collector who is collecting customer bills, the employee who is in charge of transporting the trash is sometimes constrained by finding the customer's location. In addition, related to the amount of tariff that will be charged to customers. Waste transport employees who do not know the amount of customer contribution rates will find it difficult to provide a range of rates that will be charged to customers according to the rules stated in the Pecatu village regulation. Starting from data collection in the form of observation, interviews and literature studies, then the data obtained is analyzed to create an accounting model for financial management problems and data analysis for database development as a storage medium. A system is built that can provide information to garbage
\end{abstract}


collector employees regarding the position / location of each customer's waste collection, the amount of the tariff in accordance with applicable regulations, and recapitulation of customer contribution payments. This information system can be developed based on a website with a Geographic Information System (GIS) model by utilizing Google's Application Programming Interface (API) maps feature.

Keywords : customer mapping, financial management, geographic information system

Diterima Redaksi: 25-11-2020 | Selesai Revisi: 22-01-2021 | Diterbitkan Online: 30-03-2021

DOI: https://doi.org/10.23887/janapati.v10i1.29600

\section{PENDAHULUAN}

Badan Usaha Milik Desa (BUMDesa) Catu Kwero Sedana merupakan BUMDesa yang terdapat di desa Pecatu, Kecamatan Kuta Selatan, Kabupaten Badung-Bali. BUMDesa ini didirikan berdasarkan Perdes Pecatu Nomor 1 Tahun 2014, tanggal 30 September 2014. BUMDesa ini mulai beroperasi mulai pertengahan tahun 2017 dengan satu unit usaha, yaitu unit jasa pengelolaan sampah. Sampai bulan April 2019, jumlah karyawan sebagai tenaga angkut sampah keliling sebanyak lima belas (15) orang tenaga pilah di tempat pengelolaan sampah terpadu sebanyak empat belas (14) orang, dan satu (1) orang kolektor iuran sampah, dengan daerah pelayanan hampir seluruh wilayah desa Pecatu. Untuk melayani pengangkutan sampah, unit usaha ini menggunakan tiga jenis kendaraan, yaitu sebuah kendaraan roda tiga yang memiliki bak, dua buah mobil sejenis pick up, dan sebuah truk.

Adapun mekanisme penanganan sampah yang dilakukan unit jasa pengelolaan sampah pada BUMDesa Catu Kwero Sedana ini adalah pengambilan sampah ke rumah-rumah penduduk atau tempat usaha yang ada di desa Pecatu. Sampah yang sudah dinaikkan kedalam kendaraan pengangkut kemudian dibawa ke tempat pengelolaan sampah terpadu (TPST) untuk dipilah dan diproses lebih lanjut. Setiap pelanggan yang dilayani dikenakan jasa pengangkutan sampah yang dibayar setiap satu bulan sekali dengan tarif mengacu pada peraturan desa Pecatu.

Sebagai unit usaha jasa, maka BUMDesa ini menitikberatkan pada kualitas layanan yang diberikan kepada pelanggannya. Kesulitan mencari lokasi pengambilan sampah di tempat pelanggan sering menjadi permasalahan dalam pengambilan sampah oleh staff yang belum mengetahui alamat pelanggan. Serta dalam pengelolaan keuangan atas pembayaran dari pelanggan, kolektor iuran sampah biasanya melakukan dua kali pencatatan pembayaran yang dilakukan oleh pelanggan, yaitu saat bertemu pelanggan berupa catatan manual, dan setelah sampai di kantor di input ke komputer untuk dibuatkan softcopynya. Selain itu, untuk mengetahui jumlah pelanggan seluruhnya, jumlah pelanggan yang telah membayar dan belum membayar hanya bisa diketahui ketika membuka berkas yang ada di komputer.

Sistem informasi yang dapat memetakan lokasi pelanggan serta pengelolaan keuangan atas pembayaran iuran pelanggan menjadi urgensi untuk dikerjakan yang dapat membantu BUMDesa Catu Kwero dalam memperlancar pemungutan sampah ke pelanggan serta menjaga akuntabilitas keuangan dan dapat menghasilkan laporan keuangan.

Koko Mukti Wibowo pada tahun 2015 melakukan penelitian dengan judul Sistem Informasi Geografis (SIG) Menentukan Lokasi Pertambangan Batu Bara Di Provinsi Bengkulu Berbasis Website. Metode pendekatan yang digunakan dalam penelitian ini adalah pendekatan perancangan terstruktur. Melalui pendekatan ter- struktur, permasalahan yang komplek di organisasi dapat dipecahkan dan hasil dari sistem akan mudah untuk dipelihara, fleksibel, lebih memuaskan pemakainya, mempunyai dokumentasi yang baik, tepat waktu, sesuai dengan anggaran biaya pengembangan, dapat meningkatkan produktivitas dan kualitasnya akan lebih baik. Dengan adanya Aplikasi WebGIS pusat pertambangan di Provinsi Bengkulu, pengguna diharapkan menjadi lebih mudah dalam mendapatkan informasi mengenai lokasi pertambangan di Provinsi Bengkulu [1].

Penelitian yang lain dilakukan oleh Amram Rohi Bire pada tahun 2018 dalam jurnal Bisnis dan Manajemen dengan judul penelitian Desain Model Sistem Informasi Laporan Keuangan Berbasis Web Online Bagi Koperasi Serba Usaha Tunas Mandiri di Kupang. Dalam penelitiannya, untuk menyajikan laporan keuangan, dengan bantuan desain model system informasi laporan keuangan berbasis web online bagi Koperasi Serba Usaha Tunas Mandiri Di Kupang agar dapat menyajikan 
laporan keuangan usaha dengan mudah dan transparan. Metode yang digunakan dalam penelitian ini meliputi ; Rencana Kegiatan, Studi Eksplorasi, Pra Perancangan, Perancangan, Uji Fungsi Aplikasi, dan Kajian terhadap aplikasi yang dibuat. Hasil penelitian menunjukkan bahwa Koperasi Serba Usaha Tunas Mandiri dalam hal membuat Laporan Keuangan, setelah uji fungsi dan kajian terhadap Aplikasi yang dibuat mengalami kemudahan dalam pengelolaan keuangan dan penyajian laporan yang baik [2].

\section{a. Sistem Informasi}

Sistem informasi menurut Salehfar dalam bukunya Information Systems: Introduction and Concepts, 2011. Didefinisikan menjadi "Data yang diolah menjadi bentuk yang lebih berguna dan lebih berarti bagi penerimanya". Data adalah fakta atau gambaran berbentuk mentah, data mewakili pengukuran atau pengamatan obyek-obyek kejadian kemudian data diolah menjadi informasi. Proses transformasi dari data ke informasi inilah yang disebut dengan sistem informasi [3].

\section{b. Keuangan}

Komponen dari Laporan Keuangan meliputi Neraca (Balance Sheet), Laporan Laba/ Rugi (Income Statement), Laporan Perubahan Modal/Equitas (Statement of Changes of Equity), Laporan Arus Kas (Statement of Cash Flow), dan Catatan Atas Laporan Keuangan (Notes of Financial Statement) [4]. Namun bagi institusi bisnis kecil dan menengah, laporan keuangan yang perlu disusun hanyalah tiga komponen saja, yaitu Neraca (Balance Sheet), Laporan Laba/ Rugi (Income Statement), dan Laporan Arus Kas (Statement of Cash Flow). Dalam penyusunan laporan keuangan juga dikenal istilah-istilah seperti Jurnal, Posting dan Buku Besar [5].

\section{c. Sistem Informasi Geografis (GIS)}

Pada hakikatnya Sistem Informasi Geografis adalah suatu rangkaian kegiatan yang dilakukan untuk mendapatkan gambaran situasi ruang muka bumi atau informasi tentang ruang muka bumi yang diperlukan untuk dapat menjawab atau menyelesaikan suatu masalah yang terdapat dalam ruang muka bumi yang bersangkutan. Rangkaian kegiatan tersebut meliputi pengumpulan, pemetaan, pengolahan penganalisisan dan penyajian data-data/faktafakta yang ada atau terdapat dalam ruang muka bumi tertentu. Data/fakta yang ada atau terdapat dalam ruang muka bumi tersebut, sering juga disebut sebagai data/fakta geografis atau data /fakta spasial. Hasil analisisnya disebut informasi geografis atau informasi spasial [6].

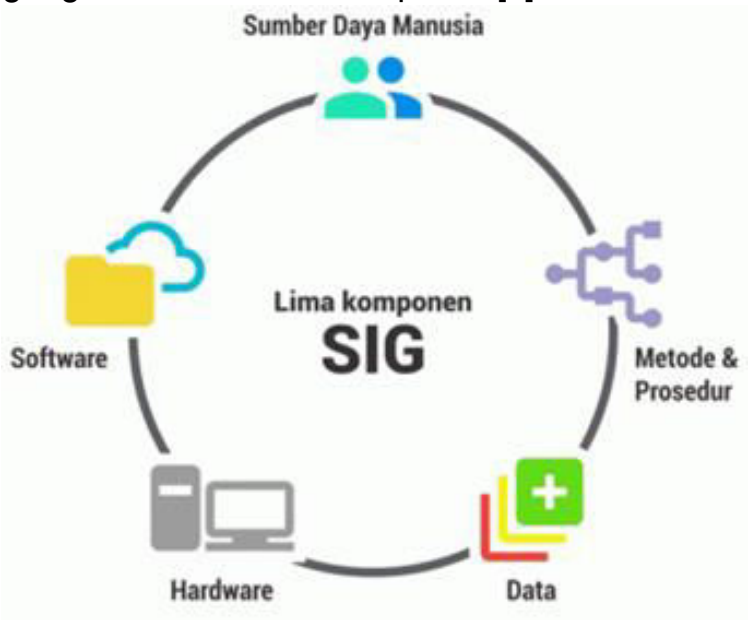

Gambar 1. Komponen SIG

SIG merupakan salah satu sistem yang kompleks dan pada umumnya juga (selain yang stand-alone) terintegrasi dengan lingkungan sistem komputer lainnya di tingkat fungsional dan jaringan (network) [7]. SIG dapat memberikan informasi seperti peta, titik koordinat, foto satelit, dan rute yang dapat mempermudah pengguna untuk mengakses lokasi yang mereka inginkan. [8][9]. SIG dapat membantu dalam pengelolaan data dan informasi berbasis lokasi sehingga dapat mempermudah pencarian data dan informasi itu sendiri [10]. Karakteristik GIS yang sifatnya berbasis lokasi sudah diimplementasikan di berbagai bidang mulai dari pemetaan bangunan 3D [11] sampai sektor krusial seperti pemetaan wilayah kebencanaan meliputi banjir dan tanah longsor [12][13].

Jika diuraikan, SIG terdiri dari beberapa komponen (sebagai berikut) dengan berbagai karakteristiknya.

1) Perangkat Keras

SIG sudah tersedia bagi berbagai platform perangkat keras; mulai dari kelas PC desktop, workstations, hingga multi-user host yang bahkan dapat digunakan oleh banyak orang secara bersamaan (simultan) dalam jaringan komputer yang luas, tersebar, berkemampuan tinggi, memiliki ruang penyimpanan (harddisk) yang besar, dan mempunyai kapasitas memori (RAM) yang besar.

2) Perangkat Lunak

SIG merupakan sistem perangkat lunak yang tersusun secara modular di mana sistem basis 
datanya memegang peranan kunci pada perangkat SIG tertentu.

3) Data \& informasi geografi

SIG dapat mengumpulkan dan menyimpan data atau informasi yang diperlukan baik secara tidak langsung maupun secara langsung.

4) Manajemen

Suatu proyek SIG akan berhasil jika dikelola dengan baik dan dikerjakan oleh orang-orang yang memiliki keahlian (kesesuaian dengan jobdescription yang bersangkutan) yang tepat pada semua tingkatan.

\section{d. Application programming Interface (API)}

Application programming interface (API) adalah kode yang memungkinkan dua program perangkat lunak untuk saling berkomunikasi. API menentukan cara yang benar bagi pengembang untuk menulis program yang meminta layanan dari sistem operasi (OS) atau aplikasi lain. API diimplementasikan oleh pemanggilan fungsi yang terdiri dari kata kerja dan kata benda. Syntax yang diperlukan dijelaskan dalam dokumentasi aplikasi yang dipanggil [14].

\section{e. Google Maps Services}

Google Maps adalah layanan gratis yang diberikan oleh Google dan sangat popular. Google Maps adalah suatu peta dunia yang dapat kita gunakan untuk melihat suatu daerah [15]. Dengan kata lain, Google Maps merupakan suatu peta yang dapat dilihat dengan menggunakan suatu browser. Kita dapat menambahkan fitur Google Maps dalam web yang telah kita buat atau pada blog kita yang berbayar maupun gratis sekalipun dengan Google Maps API. Google Maps API adalah suatu library yang berbentuk JavaScript [16].

\section{f. Database}

Database didefinisikan sebagai kumpulan data yang diorganisasi dengan cara dan aturan tertentu pada tempat penyimpanan sekunder guna merepresentasikan dunia nyata (real world), sedemikian rupa sehingga mendapatkan informasi yang diinginkan.

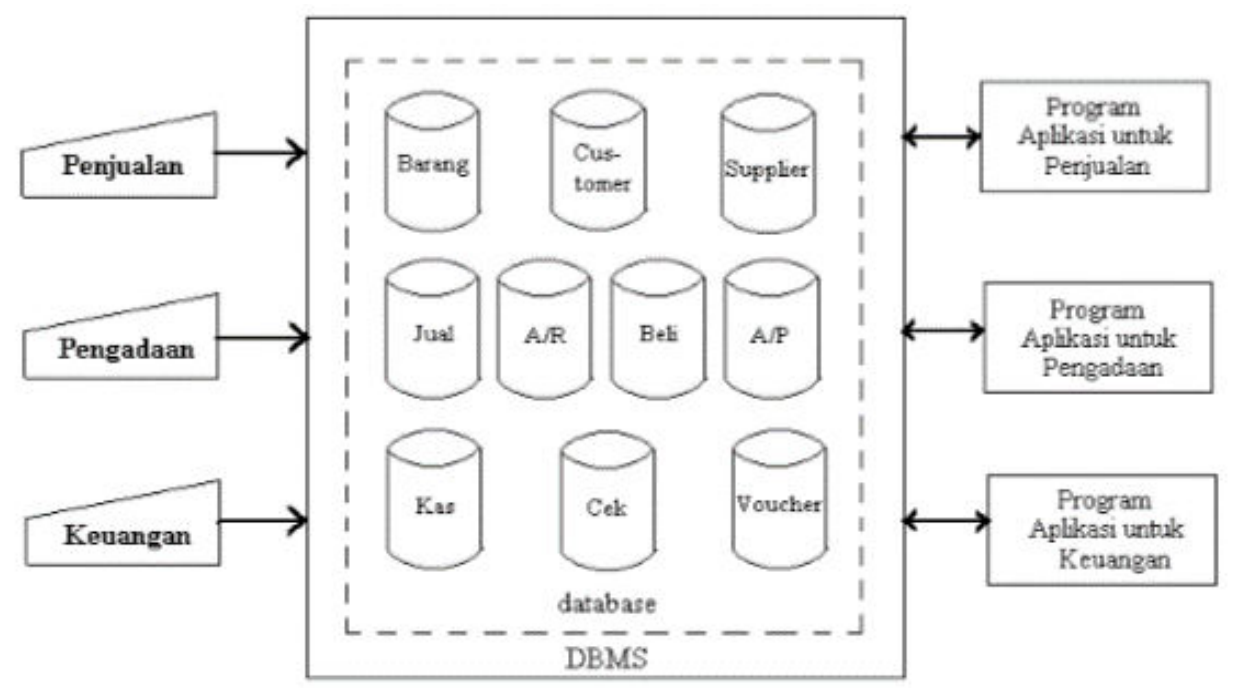

Gambar 2. Aplikasi dengan Pendekatan Database

Database adalah kumpulan data yang disimpan secara terstruktur dalam tempat penyimpanan sekunder dengan struktur yang didefinisikan [17]. Konsep database dipakai jika sistem pengolahan data suatu badan usaha (perusahaan) mempunyai beberapa seri aplikasi dengan penggunaan satu atau beberapa file untuk setiap seri aplikasinya. Sebagai gambaran, tinjau suatu aplikasi pengolahan data konvensional suatu badan usaha yang bergerak di bidang penjualan dan pembelian barang pada bagian Penjualan, Pengadaan dan Keuangan. Untuk mengatasi kelemahan pada pengolahan data konvensional, diperlukan suatu sistem informasi yang terintegrasi, yang diwujudkan melalui pendekatan penggunaan konsep database [18].

\section{METODE}

Tahapan dari penelitian ini adalah melakukan pendefinisian masalah yang ingin diselesaikan. Setelah mendefinisikan masalah yang ingin dipecahkan langkah berikutnya adalah melakukan pengumpulan data untuk 
mendukung penyelesaian permasalahan yang dihadapi. Setelah data yang diperlukan terkumpul, data dianalisis sebagai dasar dalam merancang sistem informasi geografis unit jasa pengelolaan sampah. Setelah analisis data terpenuhi, mulailah dengan merancang dilanjutkan dengan membangun sistem informasi. Sistem informasi yang dibangun hendaknya sudah dapat diimplementasikan untuk menjawab permasalahan yang ada. Jika luaran telah sesuai dengan harapan maka tahapan penelitian telah selesai.

Pengumpulan data dilakukan dengan studi literatur dan observasi pada objek penelitian.

1. Studi Literatur/Kepustakaan

Melakukan studi literatur di beberapa penelitian, jurnal yang ada dan buku sebagai referensi untuk mendapatkan acuan dalam melakukan perancangan dan pembangunan sistem informasi geografis unit jasa pengelolaan sampah.

\section{Observasi}

Kegiatan pengumpulan data dilakukan dengan mengamati proses manajemen pelanggan jasa pengelolaan sampah serta mengkaji proses kegiatan dalam mencari alamat pelanggan untuk diambil sampahnya.

\section{Wawancara}

Pada pengumpulan wawancara, peneliti melakukan wawancara kepada bapak Budi Sandika, selaku salah satu pengelola Badan Usaha Milik Desa terkait jasa pengelolaan sampah.

Penelitian ini diselesaikan dengan melalui tahapan-tahapan yang digambarkan pada flowchart sebagai berikut.

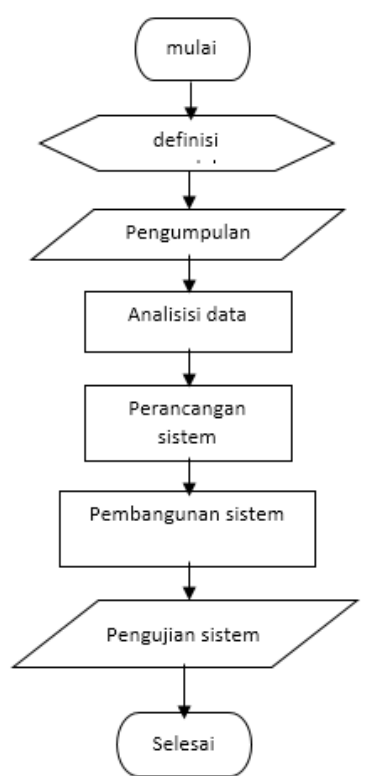

Gambar 3. Tahapan Penelitian

Hasil pelaksanaan penelitian yang telah dicapai secara umum adalah berupa perancangan dan pembangunan sistem informasi Geografis (SIG) yang mengimplementasikan proses bisnis di Unit Pengelolaan Sampah BUMDES Catu Kwero Sedana dalam mengelola proses transaksi pengambilan sampah serta pengelolaan keuangan yang ada.

Dimulai dari mendefinisikan masalah yang ada di Bumdes, di mana masalah berkaitan dengan manajemen pengangkutan sampah atas permintaan pelanggan dari sisi pelanggan yang terdaftar sebagai member maupun pelanggan yang ingin diambil sampahnya secara insidentil. Dan juga permasalahan dalam pengelolaan data di kantor Bumdes Catu Kwero Sedana, pengelolaan data keuangan. Dilanjuti dengan pengumpulan data meliputi teknik pengumpulan data melalui wawancara yaitu teknik pengumpulan data yang dilakukan melalui tatap muka dan tanya jawab langsung antara peneliti dan narasumber. Hasil wawancara berupa proses bisnis kegiatan yang sudah berjalan serta memperoleh data berupa dokumentasi yaitu metode pengumpulan data yang tidak ditujukan langsung kepada subjek penelitian. Pengumpulan dokumentasi berupa data tarif iuran pelanggan yang merupakan jenis dari dokumen primer dalam teknik pengumpulan data dokumentasi yang disajikan pada Gambar 4.

Selanjutnya, dibentuk suatu perancangan sistem berupa perancangan Conceptual Data Model dan Physical Data 
Model untuk mempermudah dalam pembangunan basis data secara relasional. Dengan perancangan yang sudah ada, dibangun sistem berbasis web dan mobile sebagai implementasi dari perancangan tersebut.

Terakhir dari tahapan penelitian adalah melakukan pengujian sistem terhadap sistem yang sudah dibangun. Pengujian dilakukan dengan blackbox testing. Black Box Testing atau yang sering dikenal dengan sebutan pengujian fungsional merupakan metode pengujian Perangkat Lunak yang digunakan untuk menguji perangkat lunak tanpa mengetahui struktur internal kode atau Program [19]. Untuk memberikan hasil pengujian dalam jalannya sistem agar dapat menghasilkan sistem yang sesuai dengan perancangan di awal dan sesuai dengan proses bisnis yang ada di Bumbes Catu Kwero Sedana.

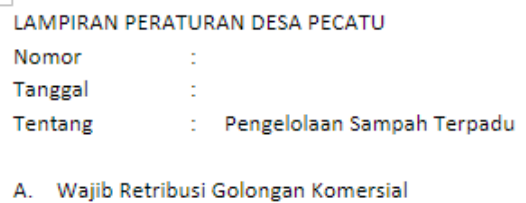

\begin{tabular}{|c|c|c|c|c|}
\hline No & Pemilik / Wajib Retribusi & Klasifikasi & Tarif $(R p)$ & Keterangan \\
\hline \multirow[t]{5}{*}{1.} & Hotel Berbintang & Bintang 5 dan di atasnya & $9.000 .000,00$ & \\
\hline & & Bintang 4 & $8.000 .000,00$ & \\
\hline & & Bintang 3 & $7.000 .000,00$ & \\
\hline & & Bintang 2 & $6.000,000,00$ & \\
\hline & & Bintang 1 & $5.000 .000,00$ & \\
\hline \multirow[t]{3}{*}{2} & Hotel Non-Bintang & Melati 3 & $3.000 .000,00$ & \\
\hline & & Melati 2 & $2.000 .000,00$ & \\
\hline & & Melati 1 & $1.000 .000,00$ & \\
\hline \multirow[t]{4}{*}{3} & Akomodasi Wisata Lainnya & Jumlah kamar $\geq 31$ & $700.000,00$ & \\
\hline & & Jumlah kamar 21 - 30 & $600.000,00$ & \\
\hline & & Jumlah kamar $11-20$ & $500.000,00$ & \\
\hline & & Jumlah kamar $\leq 10$ & $400.000,00$ & \\
\hline \multirow[t]{4}{*}{4} & Rumah Kost & Jumlah kamar $\geq 31$ & $500.000,00$ & \\
\hline & & Jumlah kamar 21 - 30 & $400.000,00$ & \\
\hline & & Jumlah kamar $11-20$ & $300.000,00$ & \\
\hline & & Jumlah kamar $\leq 10$ & $250.000,00$ & \\
\hline \multirow[t]{3}{*}{5} & Restoran / Rumah Makan & Skala besar & $3.000 .000,00$ & \\
\hline & & Skala sedang & $2.500 .000,00$ & \\
\hline & & Skala kecil & $2.000 .000,00$ & \\
\hline \multirow[t]{3}{*}{6} & Ruko / Toko & Skala besar & $500.000,00$ & \\
\hline & & Skala sedang & $400.000,00$ & \\
\hline & & Skala kecil & $300.000,00$ & \\
\hline \multirow[t]{3}{*}{7} & Warung/Usaha Dagang & Makanan & $300.000,00$ & \\
\hline & & Kelontong & $200.000,00$ & \\
\hline & & Lainnya & $100.000,00$ & \\
\hline \multirow[t]{5}{*}{8} & Pasar & Supermarket & $300.000,00$ & \\
\hline & & Minimarket & $200.000,00$ & \\
\hline & & Pasar Modern lainnya & $50.000,00$ & \\
\hline & & Pasar Desa &.- & \\
\hline & & Pasar Jenis Lainnya & & \\
\hline \multirow[t]{3}{*}{9} & Sarana Kesehatan & Rumah Sakit & & \\
\hline & & Klinik & $60.000,00$ & \\
\hline & & Apotik & $60.000,00$ & \\
\hline
\end{tabular}

Gambar 4. Data Dokumentasi luran Pelanggan

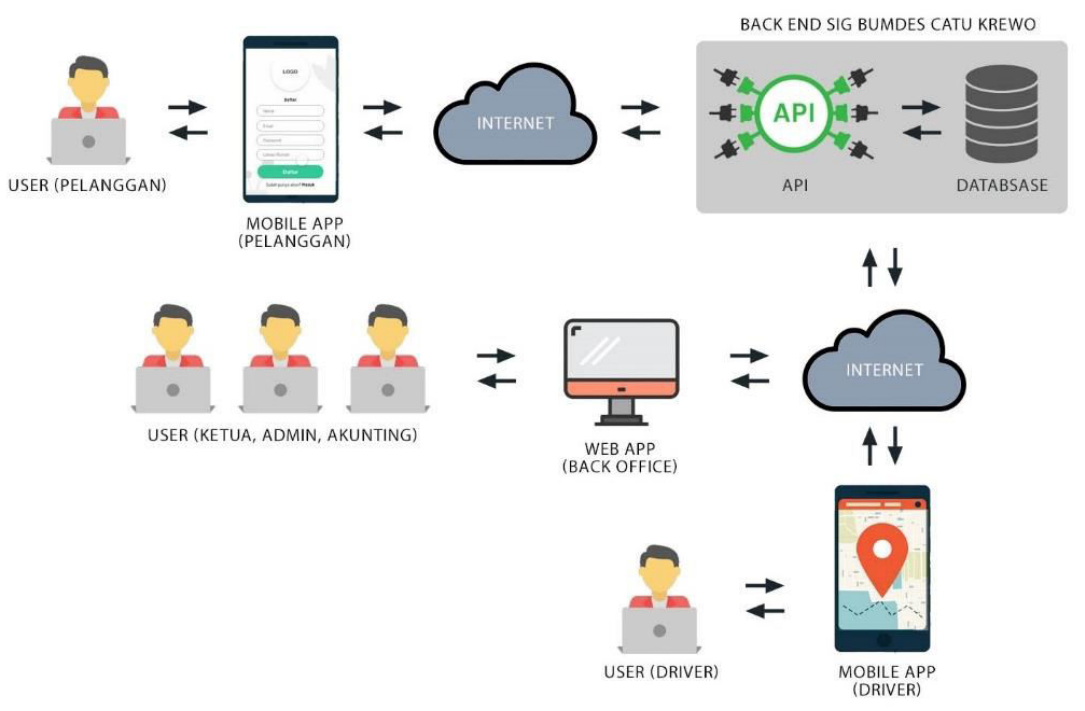


Gambar 5. Gambaran Umum Sistem

\section{HASIL DAN PEMBAHASAN}

Dari data yang diperoleh, dianalisis dengan merancang gambaran umum sistem dan struktur konsep mode data untuk menggambarkan sistem yang berjalan dan model data yang akan digunakan untuk menampung semua proses yang dilakukan di sistem nantinya. Perancangan Sistem Informasi Geografis (SIG) sebagai analisa data memperoleh perancangan sebagai berikut.

\section{a. Gambaran Umum Sistem}

Dalam memenuhi setiap kegiatan pada Bumdes Catu Kwero Sedana, pada gambaran umum sistem menyajikan kebutuhan sistem kedalam 2 platform, yaitu mobile base dan web base. Peruntukan masing-masing aplikasi berbeda sesuai level penggunanya. Perancangan sistem yang dibangun dengan memanfaatkan fitur Application Programming
Interface (API) maps yang dimiliki oleh Google serta pembangunan API (Application Programming Interface) untuk jembatan antara database dengan sistem untuk keamanan datanya. Dari data yang didapat, dianalisis pula event list yang berjalan, diantarnya pengelolaan data master (pelanggan, karyawan, kendaraan), proses validasi pelanggan yang terdaftar, pengelolaan transaksi penjadwalan pengambilan sampah pelanggan (terjadwal, insidentil), transaksi pembayaran, validasi pembayaran serta pengelolaan laporan. Dari analisa tersebut, dirancang diagram aliran data yang dapat menggambarkan aliran data yang terjadi pada sistem yang dibangun. Hasil analisis berikutnya adalah berupa rancangan dari konsep model data sebagai acuan di dalam membangun database relasional untuk mendukung penyimpanan data dalam sistem. 


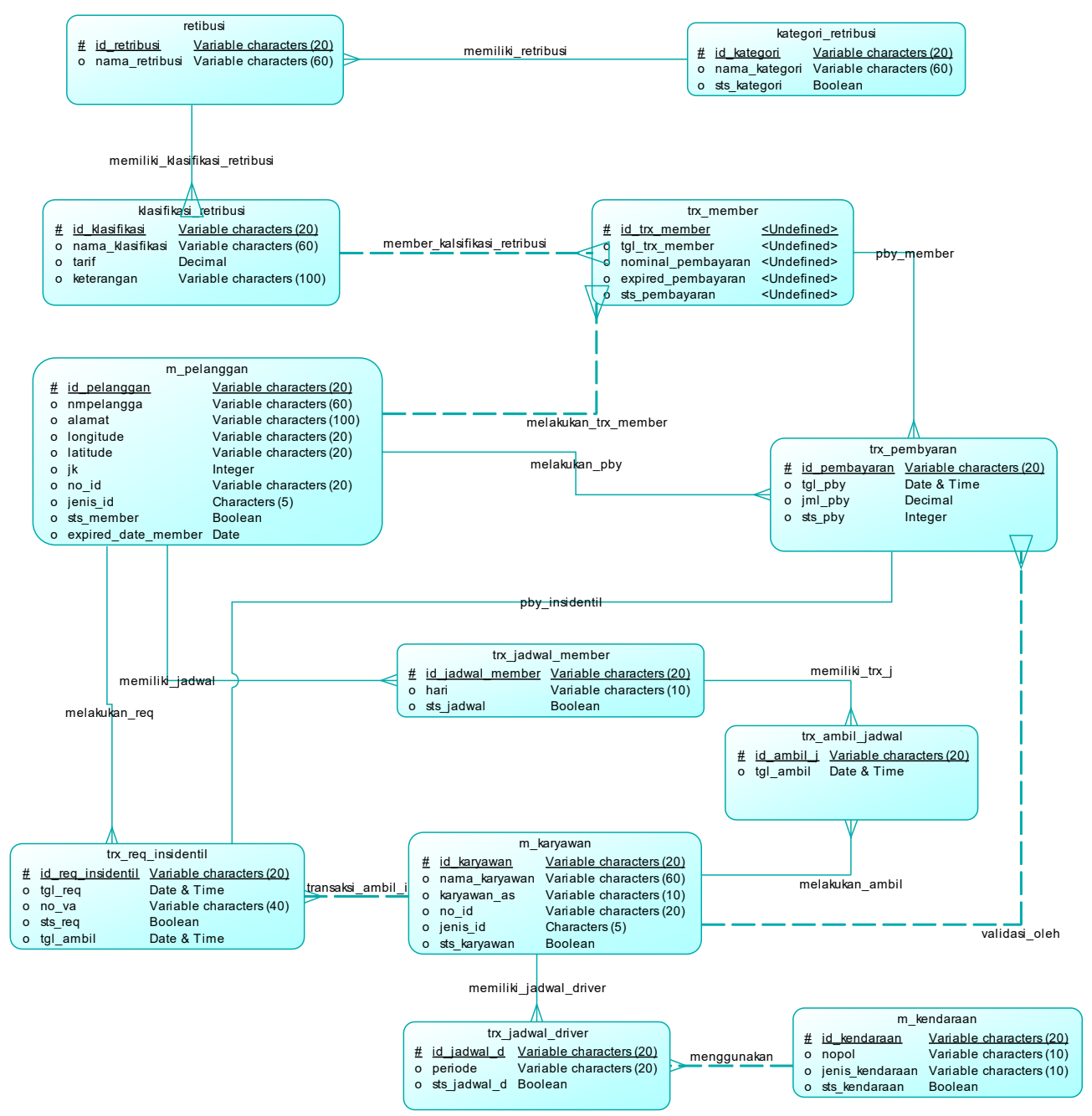

b. Conceptual Data Model

Hasil dari pengolahan data tersebut menghasilkan sebuah perancangan Conceptual Data Model (CDM). Conceptual Data Model adalah diagram grafikal yang mengambarkan keseluruhan struktur logik dari sebuah basis data. Pada model ini semua data yang ada pada dunia nyata diterjemahkan atau ditransformasikan dengan memanfaatkan sejumlah perangkat konseptual menjadi sebuah diagram data [20]. Dari CDM tersebut digenerate menjadi Physical Data Model (PDM). Gambar dari Conceptual Data Model digambarkan pada Gambar 6.

c. Physical Data Model
Physical Data Model (PDM) merupakan model yang merepresentasikan tabel yang terstruktur, termasuk nama kolom, tipe data kolom, primary key, foreign key dan relationships yang menghubungkan satu tabel dengan tabel lainnya [21]. Dengan PDM inilah struktur database relasional dapat dibuat dengan baik dalam mendukung penyimpanan data yang baik.

PDM dan CDM memiliki kemiripan dari segi entitas, atribut dan relationships. Perbedaannya yaitu pada CDM tidak terdapat foreign key, sedangkan pada PDM terdapat foreign key dimana satu tabel bergantung pada tabel lainnya. Foreign key yaitu primary key yang berada pada tabel yang memiliki hubungan dengan tabel tersebut. 


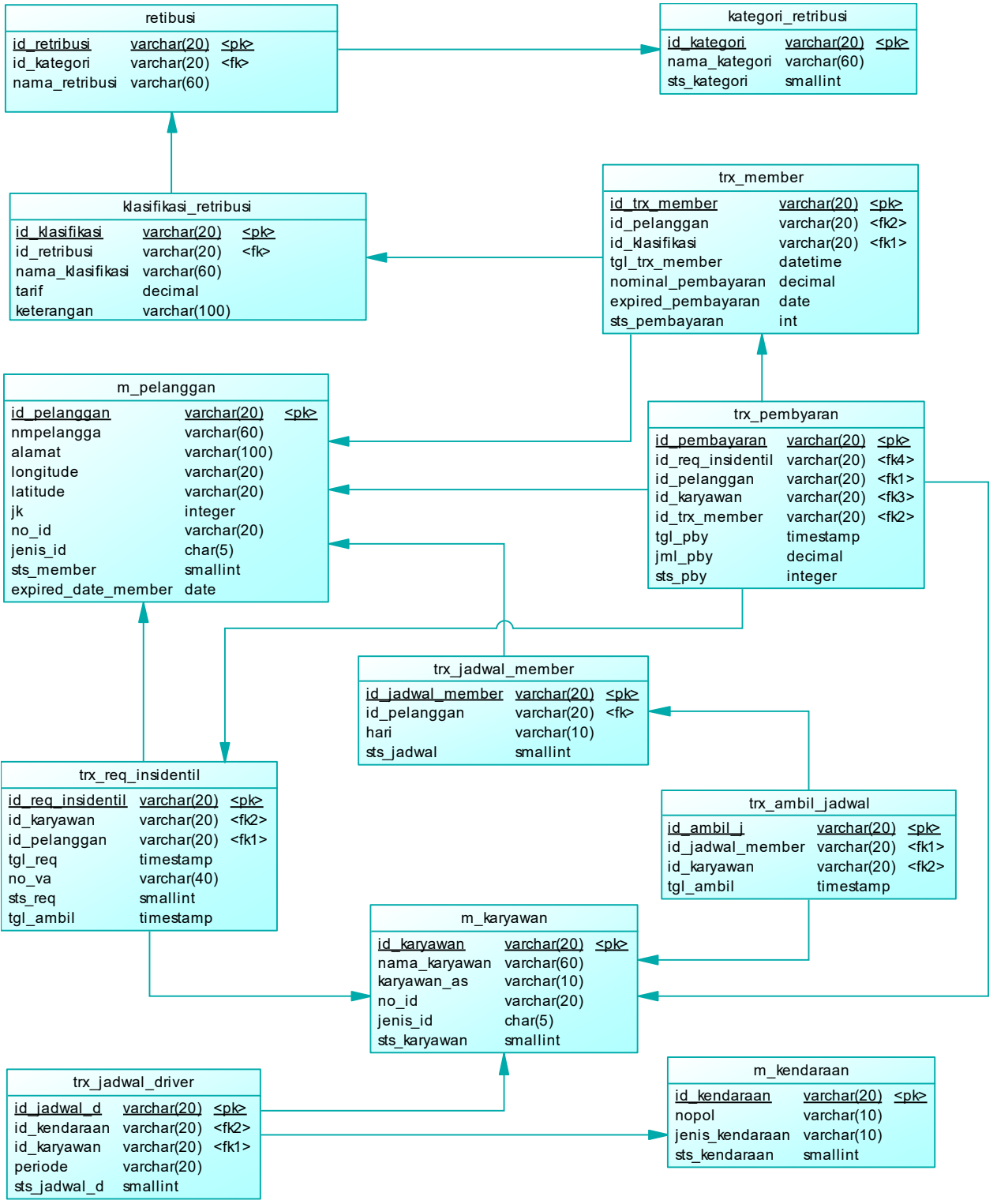

Gambar 7. Physical Data Model

Hasil dari perancangan sistem tersebut dibangun suatu back end dengan mengimplementasikan Application Programming Interface (API) yang nantinya API ini digunakan untuk settlement antara database dengan user interface yang dibangun. Pemanfaatan API ini penulis gunakan selain mempermudah dalam implementasi ke dalam sistem program, pemanfaatan API sebagai pengaman data yang baik dalam database. Selain pembangunan API, hasil dari penelitian ini adalah pemanfaatan Google Maps API dalam memetakan pelanggan BumDes Catu Kwero Sedana yang dapat mempermudah driver pengangkut sampah untuk mencari lokasi tempat penjemputan sampah.
Google Maps API dimanfaatkan untuk mempermudah memetakan suatu lokasi dengan koordinat yang disimpan sesuai dengan lokasi pelanggan.

d. Hasil user interface sistem

Hasil penelitian ini dibangun dengan dua model platform sistem, yaitu platform sistem dengan berbasis web serta mobile. Sistem berbasis web khusus diperuntukkan oleh pengelola yang bertugas di kantor BumDes Catu Kwero Sedana. Sedangkan sistem platform mobile digunakan oleh pelanggan dan driver dalam penjemputan sampak ke titik lokasi. Hasil 
dari user interface sistem dijabarkan sebagai berikut :

1) User interface berbasis mobile

Hasil sistem berbasis mobile yang dibangun sebagai hasil dari penelitian mencakup semua proses bisnis yang dirancang. Beberapa hasil penelitian berupa sistem berbasis mobile dijabarkan sebagai berikut.

a) Register member

Form ini digunakan untuk pelanggan yang ingin melakukan upgrade ke member area. $\mathrm{Di}$ form ini sudah disediakan jenis dari tipe membership yang dapat dipilih oleh pelanggan sebagai layanan yang sesuai bagi pelanggan.

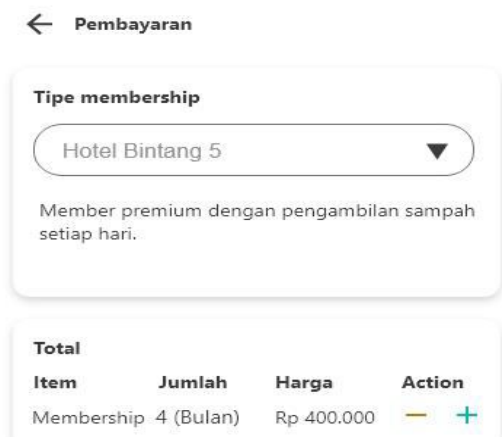

Rp 400.000

\section{Bayar}

Gambar 8. Register Member

b) Member area

Dashboard member area, berisikan informasi dari pelanggan. Dalam jendela ini berisikan infromasi expired date dari member yang disubscribe oleh pelanggan. Member area disajikan pada Gambar 9. $\leftarrow$

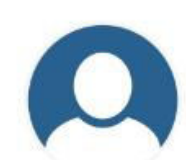

Bpk. Ahmad Asroni 081338236543

Membership

Akun membership anda akan expired

pada tanggal 20 Juni 2020 00:00

\section{Perpanjang}

Data Diri

98893477823984

Bpk. Ahmad Asroni

C. 08323123123

$\checkmark$ email@gmail.com

(- Address

\section{Gambar 9. Member Area}

c) Aktivitas rinci pelanggan

Dalam jendela aktivitas rinci pelanggan di sajikan list dari aktivitas yang sudah dilakukan terhadap layanan member yang dipilih oleh pelanggan. Aktivitas pengambilan sampah secara history akan ditampilkan dalam jendela ini, sebagai bentuk transparansi institusi pengelolaan sampah kepada pelanggan. Gambar 10 menampilkan jendela aktivitas rinci pelanggan. 


\section{Hi Bpk. Ahmad Asroni} Selamat sore!

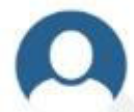

Layanan
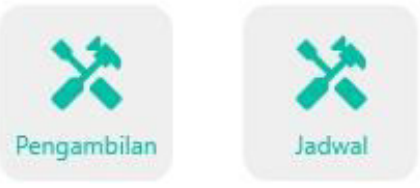

Aktifitas Terakhir

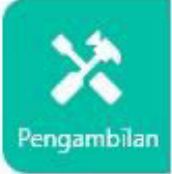

Pengambilan sampah

Harga : Rp. 10.000

Berat : $10 \mathrm{Kg}$ 20 Juni 2020 20:00

\section{Proses}

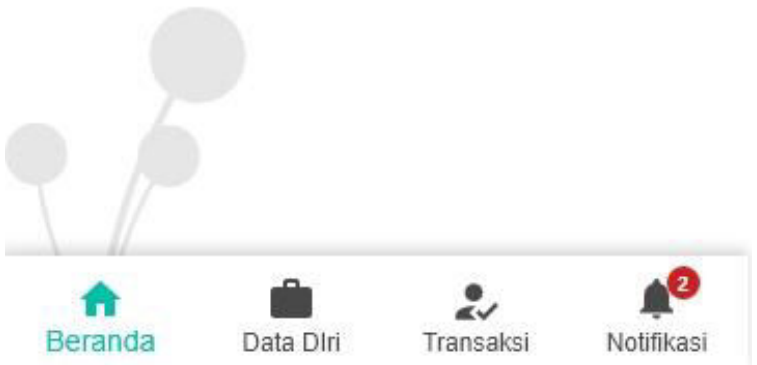

Gambar 10. Aktifitas Rinci Pelanggan

d) Pengambilan sampah insidentil

$$
\text { Selain memperoleh }
$$

layanan pengambilan sampah secara berkala, pelanggan atau user yang mengikuti layanan member ataupun tidak, juga dapat melakukan permintaan untuk pengambilan sampah secara insidentil. Pengambilan sampah secara insidentil dapat dilakukan setiap saat. Pengelolaan data terkait harga dan tipe kendaraan merupakan kebijakan dari data yang diperoleh dan dapat dilakukan pengelolaan data melalui sistem berbasis web yang dilakukan oleh staff yang ada di kantor BumDes Catu Kwero Sedana. Proses ini akan diteruskan ke staff driver berupa notifikasi yang masuk. Staff driver dapat melakukan konfirmasi terhadap permintaan dari pengambilan sampah insidentil dan sedapat mungkin untuk melakukan penjemputan sampah di lokasi pelanggan yang sudah ditetapkan lokasi serta alamatnya. Gambar 11 menampilkan form untuk melakukan permintaan pengambilan sampah secara insidentil.

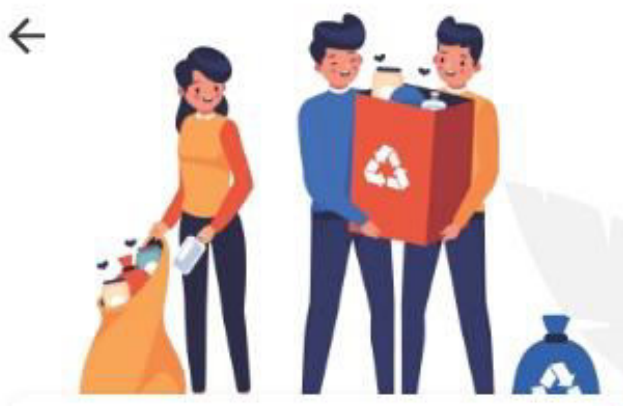

Pengambilan

20 June 2020 20:00

Lokasi Pengambilan

Jl. Raya Pecatu Gg. Mawar 33D Ganti

Tipe kendaraan

Motor / Mobil Pick up / TruclRp. 10.000

Info tambahan

sampah sudah diplastik.

Rp 10.000

Konfirmasi

Gambar 11. Pengambilan Sampah Insidentil

e) Pemilihan lokasi dengan peta

Fitur ini adalah untuk mempermudah dalam pencarian lokasi, baik dari pelanggan yang melakukan pendaftaran member saat menentukan titik lokasi penjemputan pengambilan sampah, digunakan pula oleh driver dalam pencarian lokasi untuk pengambilan sampah. Form ini mengedepankan Google Maps API untuk merancang UI. Data yang disimpan yaitu alamat berupa longitude dan latitude dari titik lokasi yang dipilih. Pemilihan lokasi dengan peta disajikan pada Gambar 12. 


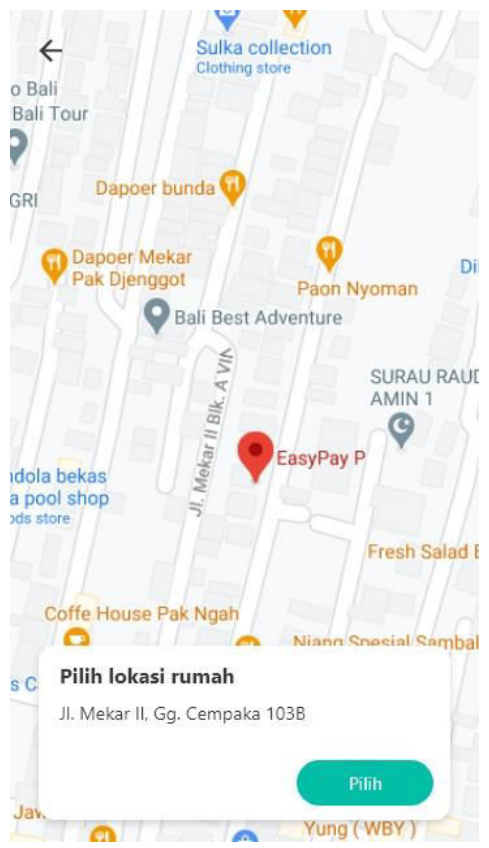

Hasil sistem berbasis web yang dibangun sebagai hasil daro penelitian mencakup semua proses bisnis di kantor Catu Kwero Sedana, mulai dari pendaftaran pelanggan, pengelolaan data karyawan, pembayaran iuran sampah, mapping jadwal driver serta laporan. Beberapa hasil penelitian berupa sistem berbasis web dijabarkan sebagai berikut.

a) Dashboard

Dalam UI Dashboard, menampilkan seluruh informasi terkait dengan total pembayaran dari subscribe member, pembayaran atas permintaan pengambilan sampah secara insidentil, informasi pembukuan serta informasi secara rinci transaksi pembayaran member dan pengambilan sampah insidentil yang dilakukan selama satu bulan di bulan yang berjalan. Dashboard disajikan pada Gambar 13.

Gambar 12. Penentuan Titik Lokasi

2) User interface berbasis web

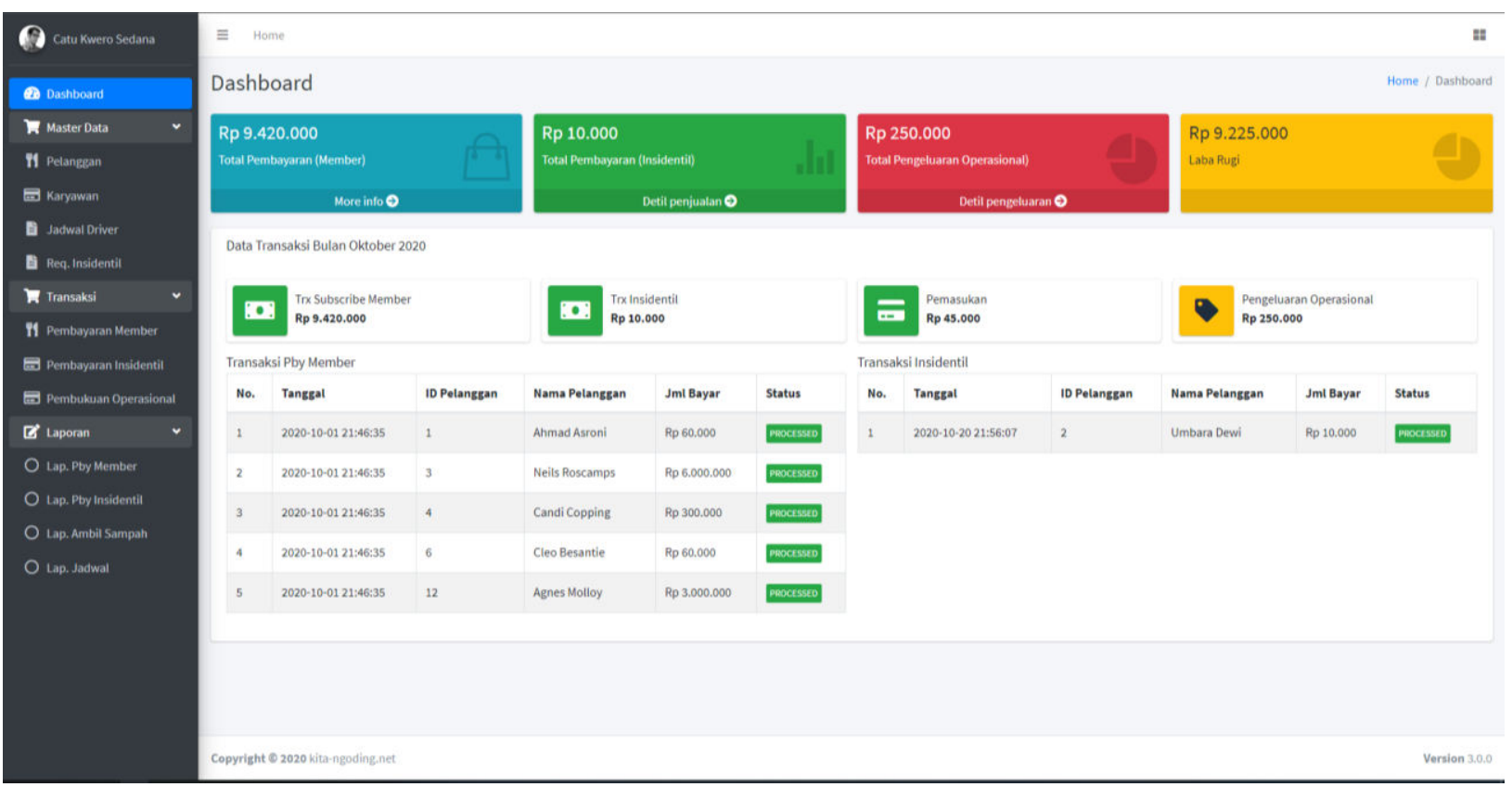

Gambar 13. Dashboard

b) Pengelolaan Master Data

Pengelolaan master data meliputi proses pengelolaan data karyawan, data kendaraan serta data pelanggan. Proses dalam pengelolaan data master hanya berfokus pada penambahan serta pencarian data master. Sebagai contoh form pengelolaan data master pada form pengelolaan data pelanggan disajikan pada Gambar 14. 


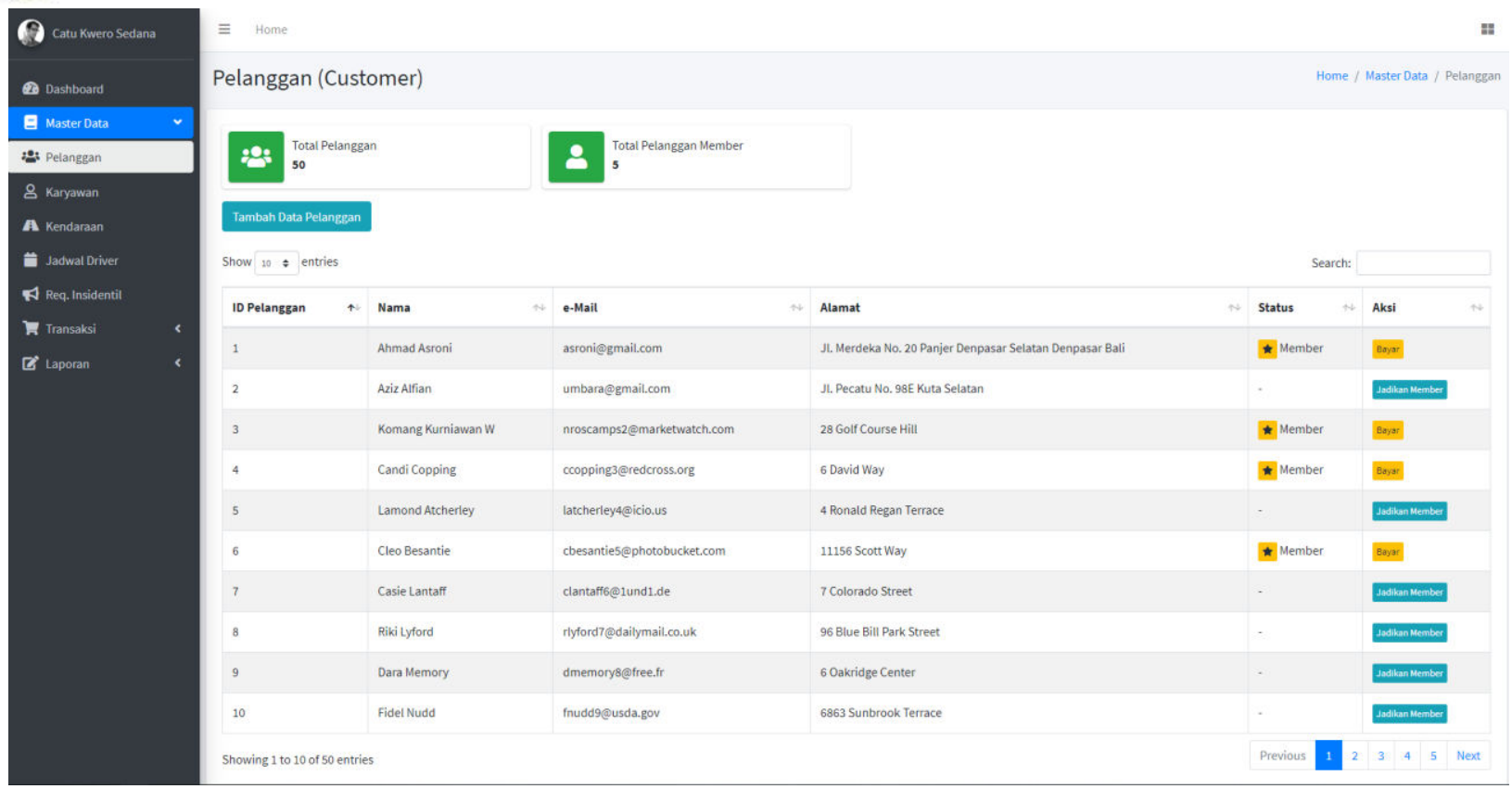

Gambar 14. Master Data Pelanggan

c) Pengelolaan Transaksi

Proses pengelolaan data transaksi meliputi proses pengelolaan transaksi pembayaran member pelanggan, pembayaran transaksi pengambilan sampah secara insidentil, pembukuan segala transaksi dalam operasional yang dibayar langsung oleh pelanggan ke kantor Bumdes Catu Kwero Sedana.

d) Laporan

Sistem menghasilkan beberapa laporan seperti laporan pembayaran member, laporan pembayaran pengambilan sampah secara insidentil, laporan history pengambilan sampah serta laporan jadwal driver.

\section{KESIMPULAN}

Sistem informasi geografis pemetaan pelanggan di unit jasa pengelolaan sampah BumDes Catu Kwero Sedana sebagai inovasi baru dalam penyajian informasi yang menawarkan banyak keunggulan dapat dimanfaatkan sebagai media penyampaian informasi yang memenuhi aspek keterkinian (up to date), kecepatan dan jangkauan yang luas. Melalui sistem informasi geografis serta pengelolaan keuangan ini penyampaian informasi lokasi pelanggan BumDes Catu Kwero Sedana dapat dilakukan secara cepat, mudah, dan luas. Membangun sebuah sistem informasi online dalam hal ini sistem informasi geografis pemetaan pelanggan unit jasa pengolahan sampah dan pengelolaan keuangan di BumDes Catu Kwero Sedana dengan menggunakan bahasa pemrograman PHP dan database MySQL, serta memanfaatkan Google Maps Api, memungkinkan terbangunnya sebuah sistem yang terintegrasi.

Pelaporan keuangan menjadi sangat effective dengan implementasi user interface yang baik dan memudahkan pengelola dalam melihat transaksi dari pelanggan. Dari hasil pengujian dengan blackbox, sistem mampu mengimplementasikan semua proses dalam perancangan sistem yang diturunkan dari proses bisnis yang ada di Bumdes Catu Kwero Sedana.

\section{UCAPAN TERIMAKASIH}

Ucapan terima kasih penulis sampaikan kepada Kementerian Riset dan Teknologi Republik Indonesia atas hibah penelitian Dosen Pemula berdasarkan Surat Keputusan Nomor 1063/LL8/PG/KM/2020 dan Lembaga Penelitian Pengabdian Masyarakat (LPPM) STIKI Indonesia atas dukungan selama penelitian ini berlangsung.

\section{REFERENSI}

[1] K. M. Wibowo, I. Kanedi, and J. Jumadi, "PERTAMBANGAN BATU BARA DI PROVINSI BENGKULU," J. Media Infotama, vol. 11, no. 1, pp. 51-60, 2015.

[2] A. R. Bire, J. A. Alang, and H. M. Sauw, "DESAIN MODEL SISTEM INFORMASI LAPORAN KEUANGAN BERBASIS WEB ONLINE BAGI KOPERASI SERBA USAHA 
TUNAS MANDIRI DI KUPANG," vol. 3, no. 1, pp. 1-8, 2018.

[3] H. Salehfar, "Information Systems: Introduction and Concepts," 2011.

[4] R. S. Sundjaja, I. Barlian, and D. P. Sundjaja, Manajemen Keuangan Edisi Ketujuh, 7th ed. Bandung: Literata Lintas Media, 2010.

[5] S. Sugiantina, "Penerapan Sistem Informasi Dalam Praktek Laporan Keuangan Sederhana," Teknologi, vol. 1, no. 1, 2012.

[6] E. V. Koroleva and Y. Y. Nikitin, "Principles of Geographic Information Sysyem," J. Multivar. Anal., 2014.

[7] B. E. Purnama, "Pembangunan Sistem Informasi Pendataan Rakyat Miskin Untuk Program Beras Miskin ( Raskin ) Pada Desa Mantren Kecamatan Kebonagung Kabupaten Pacitan," Speed, vol. 9, no. 4, p. 74, 2012.

[8] G. W. Sasmito, "Penerapan Metode Waterfall Pada Desain Sistem Informasi Geografis Industri Kabupaten Tegal," Jurnal Informatika: Jurnal Pengembangan IT, vol. 2, No. 1, pp. 6-12, 2017.

[9] L. Zahara, I. R. Munthe, A. A. Ritonga, "SISTEM INFORMASI GEOGRAFIS PEMETAAN SEKOLAH MENENGAH KEJURUAN DI KABUPATEN LABUHANBATU MENGGUNAKAN WEBGIS," Jurnal Teknologi dan Sistem Informasi (Jurteksi), vol. 7, No. 2, pp. 187194, 2017.

[10] H. Kurniawan, M. R. Tanjung, "Sistem Informasi Geografis Objek Wisata Alam di Provinsi Sumatera Utara Berbasis Mobile Android," Jurnal IImiah SISFOTENIKA, vol. 7, No. 1, pp. 13-24, 2017.

[11] A. C. Tistariawan, A. L. Nugraha, and B. Sasmito, "VISUALISASI MODEL 3D KAMPUS DEPARTEMEN TENIK GEODESI FAKULTAS TEKNIK UNIVERSITAS DIPONEGORO," Jurnal Geodesi Undip, vol. 10, no. 2, pp. 118-124,
Apr. 2021.

[12] D. E. Frizani, A. L. Nugraha, and M. Awwaluddin, "PENGEMBANGAN WEBGIS UNTUK INFORMASI KERENTANAN TERHADAP ANCAMAN BANJIR," Jurnal Geodesi Undip, vol. 10, no. 2, pp. 11-18, Apr. 2021.

[13] N. W. Sholekhah, A. L. Nugraha, and M. Awwaluddin, "ANALISIS ANCAMAN TERHADAP BENCANA BANJIR DAN TANAH LONGSOR PADA WILAYAH PERMUKIMAN DI KABUPATEN JEPARA," Jurnal Geodesi Undip, vol. 10, no. 2, pp. 29-35, Apr. 2021.

[14] M. Meng, S. Steinhardt, and A. Schubert, "Application programming interface documentation: What do software developers want?," J. Tech. Writ. Commun., vol. 48, no. 3, pp. 295-330, 2018.

[15] M. Konarski and W. Zabierowski, "Using google maps API along with technology .NET," Mod. Probl. Radio Eng. Telecommun. Comput. Sci. - Proc. 10th Int. Conf. TCSET'2010, no. January 2010, pp. 180-182, 2010.

[16] A. Dincer and B. Uraz, Google Maps JavaScript API Cookbook. 2013.

[17] R. Elmasri and S. B. Navathe, Fundamentals of Database Systems, Sixth. New York: Pearson, 2010.

[18] E. Derclaye, "What is a Database?," J. World Intellect. Prop., vol. 5, no. 6, pp. 981-1011, 2005.

[19] S. Nidhra and J. Dondeti, "BLACK BOX AND WHITE BOX TESTING TECHNIQUES -A LITERATURE REVIEW," Int. J. Embed. Syst. Appl., vol. 2, no. 2, 2012.

[20] D. Embley and B. Thalheim, "Handbook of Conceptual Modeling. Theory, practice, and research challenges," no. March, 2016.

[21] "Data Modeling - From Conceptual Model to DBMS," no. Sparx Systems, p. 18, 2011. 